\title{
By Their Proverbs we shall Know Them: Understanding the Yorùbá's Perception of Wisdom in the Context of Proverbial Expressions
}

\author{
Olajuyin Oyebanji Anthony \\ Senior Lecturer \\ Department of Ear, Nose and Throat Surgery \\ Faculty of Clinical Sciences \\ College of Medicine \\ Ekiti State University \\ Ado-Ekiti.Ekiti State Nigeria.
}

\begin{abstract}
In spite of the huge number of past and present researches on wisdom, more about this construct remains cryptic. Various approaches have been adopted by the Cognoscenti to understand the nature of wisdom. One of such approaches is the implicit theory of wisdom. This is concerned with the search for an understanding of people's folk conceptions of what wisdom is. The goal of this work is to examine the perception of wisdom among the Yoruba with a view to understand its characteristic features from proverbial perspectives. Fifteen Yoruba proverbs and idiomatic expressions that fulfill the study criteria were collated and analyzed. The study noted that Yoruba perceives wisdom as a distinct virtue that grows and develops with life experiences. It reaffirmed the universality of wisdom and that nobody has monopoly of wisdom. However, the findings show the tendency to exploit or cheat under the guise of being wise. To this end, the Yorùbá in their wisdom had coined proverbs to teach the cheat that what he or she considers as wisdom is in fact stupidity. Overall, the Yoruba perceives wisdom as a universal virtue that helps human being to understand deal with and succeed in the world without hurting the soul of mankind.
\end{abstract}

Keywords: Perception, Wisdom, Proverbs, Yorùbá

\subsection{Introduction}

Every cognitively normal child is born with the potential to develop in wisdom. However, such potential is rudimentary at birth since a baby cannot be as wise as when he or she grows to adulthood. Although, its developmental milestone is not fully understood, observations have shown that wisdom develops in relation to life experiences. It also appears that a relationship exists between wisdom and aging hence the popular aphorism: "A fool at forty is a fool forever". Attempts to define wisdom have only yielded diverse alternatives. The Longman Dictionary of Contemporary English defines wisdom as a good sense and judgment based on experience of life. Clayton (1982) defined wisdom as the ability to grasp human nature, which is paradoxical, contradictory, and subject to continual change. Baltes and Staudinger (1993) wrote; wisdom is good judgment and advice in important but uncertain matters of life. In the ancient Greek, wisdom was considered an important virtue, personified as the goddesses of Metis and Athena. The ancient Romans valued wisdom as skillful knowledge and chastity, personified in Minerva, the goddess of wisdom (Wikipedia, 2018). In the Holy Bible, wisdom was personified by King Solomon as someone with ability to guide and guard against trouble as he wrote in the book of proverb;

"Listen! Wisdom is calling out in the streets and market places, calling loudly at the city gates and wherever people come together: "Foolish people! How long do you want to be foolish? How long will you enjoy pouring scorn on knowledge? Will you never learn? Listen when I reprimand you; I will give you good advice and share my knowledge with you. I have been calling you, inviting you to come, but you would not listen. You paid no attention to me. You have ignored all my advice and have not been willing to let me correct you. So when you get into trouble, I will laugh at you, I will mock you when terror strikes, when it comes on you like a storm, bringing fierce winds of trouble, and you are in pain and misery. Then you will call for wisdom but I will not answer. You may look for me everywhere but you will not find me". (Proverb 1, 20 - 28) 
From this Biblical perspective, it would appear that wisdom has roles to play in the promotion of well-being of human being. The association between wisdom and well-being has been an area of intense research activities among workers. It is noteworthy that different types of wisdom have been recognized. In one classification, wisdom was grouped into secular and divine wisdom. Secular wisdom is that which is bestowed on everyone thus, universal in its distribution while divine wisdom is spiritual, given to someone through prayer. At least, it was through prayer that King Solomon received the divine wisdom with which he delivered the great judgment which no King before him had ever delivered. In another write-up, wisdom was classified into personal and general.

Personal wisdom refers to individuals' insight into their selves, their own lives while general wisdom is concerned with individuals' insights into life in general, from an observer's point of view, that is, when they are not personally concerned(Staudinger \&Glück, 2011). Although wisdom, like any other creation, is a gift from God, its growth and development is partly influenced by life experiences. Indeed, a review of the literatures shows that wisdom undergoes certain evolution as individual interacts with the world.

\subsection{Wisdom, Intelligence, Knowledge and Proverbs}

Wisdom is a distinct virtue hence must be distinguished from other seemingly similar virtues in order to understand its specific features. First is to distinguish wisdom from intelligence. As noted by scholar, both wisdom and intelligence may be phenotypically similar, yet are not identical. The function of intelligence is characterized as focusing on questions of how to do and accomplish necessary life-supporting tasks while the function of wisdom is characterized as provoking the individual to consider the consequences of his actions both to self and their effects on others Clayton (1982). Also, the wise individual is perceived to have much the same analytical reasoning ability that is found in the intelligent individual. But the wise person has a certain sagacity not necessarily found in the intelligent person (Sternberg (1985).As regards knowledge, it is a common pitfall to apply this virtue in lieu of wisdom. This act as noted by writers; is not only erroneous but also hazardous. In sensitive or complex tasks for instance, the use of knowledge in lieu of wisdom can be counterproductive. This was the view of Sir Robert Hutchinson" as he prayed in his 'medical litany':

From inability to leave well alone,

From too much zeal for what is new and contempt for what is old,

From putting knowledge before wisdom, science before art, cleverness before common sense,

From treating patients as cases, and

From making the cure of a disease more grievous than its endurance,

Good Lord, deliver us". (Bailey and Love, 2008)

${ }^{\dagger}$ Sir Robert Hutchinson, 1871-1960, was Consulting Physician to the London Hospital and President of the Royal College of Physicians.

Experts have attempted to distinguish between wisdom and knowledge in their literary works. One of such experts is William Cowper (1978) who wrote,

"Knowledge and Wisdom, far from being one, have oft-times no connexion. Knowledge dwells in heads replete with thoughts of other men; Wisdom in minds attentive to their own. Knowledge is proud that he has learned so much; Wisdom is humble that he knows no more".

Also, Ardelt (2000) remarked: "Whereas intellectual knowledge enables elderly people to stay involved in worldly affairs, wisdom-related knowledge helps them to prepare for the physical and social decline of old age and ultimately their own death"

To understand the differences between wisdom and proverb is to juxtapose the two constructs. First is to compare them in terms of definition. Just like wisdom, there is no way the essential ingredients of all the available proverbs can be captured in a single phrase or sentence as definition.

'It is difficult to arrive at universally acceptable and unambiguous proverb markers that would enable us to identify positively a sentence as proverbial. Wolfgang Mieder, cited by Fasiku (2006, pg. 50)

A remark by Trench (1905, pg 7) says: 'Nothing is harder than a definition. While on the one hand, there is for the most part no easier task than to detect a fault or flaw in the definitions of those who have gone before us, nothing on the other hand, is more difficult than to propose one of our own, which shall not also present a vulnerable side'.

A common denominator for the inability of researchers to find a universally acceptable definition each for wisdom and proverb is their wide applications. As noted, proverb deals with all aspects of life. It is a linguistic 118 
metaphorical expression of truth which cuts across all strata of human life (Adamo 2015). This also applies to wisdom as it cuts across all strata of human life. Other feature that may blur the distinction between wisdom and proverb is their thought-provoking features. This is why proverb is sometimes referred to as a wise-saying. Of course, proverb is the saying of the wise. Indeed proverb is a linguistic output from the fountain of wisdom. These relationships notwithstanding, wisdom and proverb are conceptually not the same, even in their thoughtprovoking capabilities; wisdom is 'implosive' while proverb is 'explosive'.

From these comparative analyses, it is obvious that wisdom is in no way synonymous with other highlighted virtues. Indeed, others may fail, wisdom cannot fail, others may fade, wisdom is distinct, others may vary, wisdom is constant, others may be deep, wisdom is deeper and others may be wide, wisdom is wider in spectrum.

\subsection{Literature Review}

Literature is a washed with studies on wisdom. Since the 1970's, five main areas have been established: lay definitions of wisdom, conceptualizing and measuring wisdom, understanding the development of wisdom, investigating the plasticity of wisdom, and applying psychological knowledge about wisdom in life contexts (Staudinger \& Glück, 2011). In a study, Zacher \& Staudinger (2018) reviewed and discussed the association between wisdom and well-being. The study, which particularly focused on the relationship between wisdom and subjective well-being (SWB) and psychological well-being (PWB) indicated the areas that require further studies. In a similar study, Ardelt (2000) examines the relationship between wisdom and aging well. In this longitudinal study, the researcher found wisdom to be an important predictor of aging well. The specific role of wisdom and intellectual knowledge at enhancing the well-being particularly in the twilight of life was another study of Ardelt (2000). It was the measurement of wisdom in concrete terms that drew the attention of Brown \& Greene (2006) and the approaches to learning and studying wisdom was the focus of Sternberg (1985). Over the years, the approaches adopted by researchers to investigate wisdom vary partly with their research interests. Among these are philosophical, implicit-theoretical and explicit-theoretical approaches (Sternberg 2001). In the philosophical approach, wisdom is seen as (a) sophia, which is found in those who seek a contemplative life in search of truth; (b) phronesis, which is the kind of practical wisdom shown by statesmen and legislators; and (c) episteme, which is found in those who understand things from a scientific point of view(Sternberg, 2001). The implicit-theoretical approaches have in common the search for an understanding of people's folk conceptions of what wisdom is. Thus, the goal is not to provide a "psychologically true" account of wisdom, but rather an account that is true with respect to people's beliefs, whether these beliefs are right or wrong (Sternberg, 2001). In another work, Sternberg noted that implicit theories are constructions by people (whether psychologists or laypersons) that reside in the minds of these individuals. Such theories need to be discovered rather than invented because they already exist, in some form, in people's heads. He went further to note that discovering implicit theories can be useful in helping to formulate the common-cultural views that dominate thinking about a given psychological construct, whether the culture be one of people, in general, or of psychologists, in particular. Also, understanding implicit theories can help us understand or provide bases for explicit theories, because explicit theories derive, in part, from scientists' implicit theories of the construct under investigation (Sternberg, 1985). As regards the explicit-theoretical approaches, they have in common a formal theory of wisdom that is proposed to account for wisdom.

\subsection{Theoretical Framework}

This work shall seek to understand wisdom in the context of people's implicit theory of wisdom. As earlier noted, the implicit theory is a construct that reside in the minds of the people. Thus, the goal of this work is to discuss the perception of wisdom among the Yorùbáin the context of proverbial expressions. That is, to X-ray theYorùbá's perception of wisdom using proverbial expressions as the research markers. As known, proverb constitutes the worldview of a people. It exposes the cryptic attributes of cultures and customs. It is a linguistic password for the encrypted features of dominant attitudes and cultures. It is a lingual manifestation of thoughts of the wise and a reflection of the ideology and tradition of a people.

“.....proverbs encapsulate the worldview of a people, and serve as a means of arousing, defining, manifesting and establishing the expectations, aspirations and consciousness of a people....proverb serves as a linguistic confirmation of the totality of a people's worldview and the epistemic cognition of this worldview". (Fasiku 2006:25).

In many African languages, proverbs act as a catalyst of knowledge,wisdom, philosophy, ethics and morals (Adeyemi and Salawudeen 2014). Aside the aesthetic and figurative value in proverbs, it presents a graphic 
statement that expresses a truth of experience (Ademowo andBalogun2014). From these submissions, it is obvious that the true reflection of the people's perception of wisdom can be seen through proverbs especially among the Yorùbáwhose life and cultures are richly endowed with proverbs. To this end, some proverbs were selected as searchlights in this study to investigate the perception of wisdom among theYorùbá.

\subsection{Methodology}

Fifteen proverbs ofYorùbá extraction were selected for this work. Most ofthe proverbs were conceptually congruent and were categorized as such. The existence of congruent proverbs follows the practice of Yorùbá at saying one thing in different ways. The purpose is to emphasize the concept and contents of the proverbial expressions. In this study, the elements of each proverb were highlighted. The conception and perception of wisdom in the context of proverbs among the Yorùbá were analyzed and the application of proverbial wisdom in all sphere of human endeavour were discussed. These were related with findings of other workers and the discussion was concluded with the limitation and areas for future studies.

\subsection{Data Analysis}

As earlier noted, wisdom is a distinct phenomenon. It is one of those virtues with psycho-cognitive components. Although, wisdom is not physically visible, its nature, antecedents and effects are vividly seen in various human endeavours. Over the years, the Yorùbá has studied and noted the features that characterize a virtue as wisdom. These features in the context of the implicit theory have been captured and expressed in theYorùbá proverbial expressions. It is the purpose of this paper to categorize and analyze some of these proverbs so as to understand the Yorùbá's perception of wisdom. First to be considered is the proverb that depicts wisdom as a sense of understanding and good judgement.

\section{1"Ogbọn la fi ń pa àmúkùruepọn"}

It is with wisdom that a black fly on the scrotum is killed

Àmúkùru is the Yoruba name for black fly. The black fly is the vector of the disease called onchocerciasis or river blindness. The fly feeds on human blood hence perches anywhere on the body in search of its daily bread. Commonly, it perches on the scrotum (epon) of the traditional African farmers by whom this proverb was coined. The scrotum is accessible to the black fly because the dress of most traditional African farmers is short and loose and in most cases is worn without underwear. Also, the black fly is attracted to the scrotum because it is kept warm and hidden away from view. To kill a black fly on the scrotum is not only a sensitive but also a complex task for the following reasons. Firstly, the scrotum contains the testes that are very sensitive to touch. Secondly, the black fly on the scrotum is hidden from view and any attempt to kill it will amount to a blind act. Thirdly, the bite of a black fly is brisk and painful hence may elicit violent, unguided slap on the scrotum. If this happens, the victim will feel pain in the abdomen - the original site of the testes (The testes develop from the abdomen and gradually descend to the scrotum at birth). Fourthly, hitting a fly against the scrotum will not just cause abdominal pain but may fail to kill the fly because the scrotum is a soft tissue hence any force to kill a small fly on it will be dampened by the softness of the scrotum. Therefore, killing a black fly on the scrotum is a task that requires a sense of understanding and good judgement to accomplish. It is this sense of understanding and good judgement that constitutes wisdom as stated in the above proverb. Thus, wisdom is perceived by the Yorùbáas a sense of understanding and good judgement with ability to resolve sensitive and complex issues of life. Also the proverb connotes that, whatever the wisdom resolves, it resolves it satisfactorily. This was corroborated by Sternberg (1985).

".........the solutions that are offered (by the wise individual) to complex problems tend to be the right ones" The proverb is useful in conflict resolution or any complex issue that can be likened to killing a black fly on the scrotum. In such circumstances, the proverb reminds the stakeholders of the need to exercise wisdom at resolving the conflict less the intervention becomes a double-edged sword similar to causing abdominal pain in attempts to kill a black a fly on the scrotum. It is an advisory or counseling proverb to encourage people to apply wisdom in dealing with complex issues of life. This ability of wisdom to resolve complex issues satisfactorily is reflected in the next proverb.

\section{2"Ologbọn di oríejamú, àìgbọn di ìdírẹmú"}


A wise person holds fish by the head while the fool holds it by the tail This proverb illustrates wisdom in action. It tells the functional attributes of wisdom. Holding up a fish by the tail is not only ineffective; it is hazardous because the sharp, pointed spikes in some fish can prick the skin as the fish wriggles. To avoid such injury, the fish must be held on the head and the spikes close to the head splayed and steadied with fingers. With such handling, the fish is held captive and a sensation of captivity is felt by the fish. This causes the fish to remain calm. The sense of holding the fish appropriately is what the Yorùbárefers to in this proverb as wisdom. This again reaffirms the perception among the Yorùbáthat wisdom is a sense of understanding and good judgement and that whatever wisdom does, it does it appropriately.

Furthermore, that a wise man has the options of holding a fish by the head or tail but chooses the head shows that he knows the consequences of his decision. This concurs with the remarks of Sternberg (1985):

".........wise people are able to make clear, sensible, and fair judgments and knowing the consequences of the decisions"

In a simple test by this author, two people were separately told to keep a standing fan with them while sitting on a passenger seat in front of a cab. The subjects were not allowed to witness each other and only one attempt was allowed to avoid trial-and-error and there was no evidence of previous attempts in their life time. The first person firstly placed the fan on the front seat close to the driver before attempting to sit but find it difficult to sit down. The second person firstly sat on the passenger seat and placed the fan obliquely across the chest and lap. From this simple test, it is clear that the second subject was wise and was able to understand the consequences of placing the fan either way before choosing the better option. Although the first subject may be intelligent, he did not foresee the consequence of his action and chose a wrong method from the onset. This proverb is used to warn people against taking unnecessary risks when there are safer options and to follow the path of wisdom. In the next proverb, the association between wisdom and leadership is illustrated as the proverb describes the wisdom as the hallmark of a good leadership.

4.3 "Bíòwe, bíòwe, là ń lùlùòidigbó,ologbonló ń jóo, omorànló ń mo-ọn"

Drumming of (Ògìigbó) is proverbially encoded, only the wise men can dance to it andonly the informed persons can decode it

Ògìdigbóis a drum of war (Olatunji 2012). It is played in proverbial notesto send message to the warriors at the war front. War, as we all know requires tactical moves and decisions that are not known to the enemies. Thus, the Yoruba has devised proverbial drumming as a cryptic means to induce tactical manoeuvres among the warriors in the battle front. However, the effective use of the drumming for tactical movements and manoeuvres depends on the ability of any warrior to decode the messages of the Ògìdigbó drumming. As expressed, it is only the wise men that discern it. Thus, the warriors (leaders) who discern the drumming are versed in proverbs and endowed with wisdom. Wisdom in this context implies a sense of understanding, good judgment and ability to listen and decode information. The proverb brings into focus the need fora leader to exercise wisdom in dealing with the subordinates. A good leader must be attentive, have listening ears and be able to read the minds of the people. He must look before he leaps. It is then he or she will be able to induce the necessary 'tactical movements and manoeuvres' among the subordinates. The proverb is a reminder that only the wise individual with a sense of understanding and good judgment should be entrusted with leadership position. This is because only a wise leader would be able to read between the lines, take appropriate decisions and know the consequences of their actions.

\section{4 "Bí mi ò tiẹkà 'wé, mokaogboninú mi”"}

\section{Even, if I'm not formally learned, I'm learned in wisdom}

The above proverb is meant to distinguish between wisdom and knowledge. As previously stated wisdom and knowledge may mimic but are not synonymous. Thus, attempts have been made by the Yoruba to emphasize this fact through proverbial expressions. In this proverb, the non-learned boasts of wisdom despite the inability to read and write. Two contrasting features are encoded in this proverb - learned and unlearned. While knowledge and wisdom may overlap in the former, the distinction becomes clearer in the latter when wisdom is viewed in the context of those without formal education. As shown in the first part of the proverb, the speaker though lacks knowledge (formal education), is full of wisdom. This distinction is luminous enough particularly for someone whose mind may be too cloudy as to appreciate the difference between wisdom and knowledge.

It is a proverb of reaction often used to show disapproval that wisdom cannot be substituted with knowledge in any circumstance. It is particularly used in meetings or deliberations when sometimes the learned side-line the 
non-learned in the belief that the issue at stake can be resolved only with knowledge. Ironically, many of the learned folks may lack the necessary wisdom-related experience to resolve the prevailing issues at hand. Thus, the proverb enables those who may be denied of their wealth of experience to have a say in gatherings and meetings. It also reminds the stakeholders that anyone and indeed everyone, learned or non-learned, young or old is endowed with wisdom as reflected in the next proverb.

\section{5"Omodégbọn, àgbàgbọn la fi dállẹ-Ifẹ"}

Ilẹ-Ifẹwas founded on the wisdom of both the young and the old

Ilẹ-Ifẹ was the cradle of the Yorùbá. In Yorùbáparlance, it is referred to as Orísun (The Source). In everyday interactions and communications, references are often made to 'The Source' especially on issues that relate with cultural values. For instance, it is common to hear:

“A kiìdúrók'oban'Ílẹ-Ifẹ, a kìibẹerẹ'ọban'Ílẹ-Ifẹ, kòdúró, kòbẹrẹlà ń k’ọban'Ílẹ-Ifẹ, İdobálẹlà ń k’ọban'ÍlẹIfẹníbitíojúmoti ń mowás 'íléayé”

We don't stand to greet the King in Ile-Ife, we don't squat to greet the King in Ile-Ife, it is neither standing nor squatting that we greet the King in Ile-Ife; it is by prostrating that we greet the king in Ile-Ife, a city of sunrise.

Such is the composition of various dictum and axioms in Ile-Ife as depicted by the above proverb. The proverb refers to the belief in Ile-Ife that wisdom is universal. Of course, whatever is believed in Ile-Ife, the cradle of Yorùbáto be universal is truly universal among the Yorùbá. Perhaps, it is the emphasis on this universality of wisdom that prompted the emergence of the following Yorùbáfolklore;

In the folklore, wisdom was figuratively depicted as an item that is picked up on the streets and discarded after use. One day, the Tortoise wanted to remove all the wisdom from the streets so he could be the only custodian of wisdom in the world. To achieve his goal, he began to move from one point to another picking and dropping wisdom into a gourd. Having satisfied himself to have removed all the wisdom from the world, he sealed and suspended the wisdom-filled gourd with its rope hung onto his neck and the gourd in front of his abdomen, while looking for a palm tree on which to hide the gourd. On seeing a palm tree, he began to climb but with difficulty because the gourd before him would not allow him. While struggling to climb the palm tree, a hunter who was passing by saw the Tortoise and offered to help. He said, "why not rotate the gourd from the front to the back so that your belly can be in contact with the palm tree. He did as the hunter recommended. Lo and behold, he climbed the palm tree to the top in a twinkle of an eye. Realizing his folly, he looked down from the top and pondered, 'so, there remains on earth, wisdom, despite my efforts at being the only custodian of wisdom in the world'. He said; 'surely there is no way I could have monopoly of wisdom'

Truly, nobody could have the monopoly of wisdom. This is the perception of the Yorùbáas noted from experience and expressed in the above proverb. The implication of this is that human beings are interdependent and no man is an island. People must cooperate and share ideas if they must grow in wisdom. The proverb is used to promote democratic ideals, justice and fair play and to emphasize the importance of interdependency among the people. Such interdependency is also reflected in the following set of three proverbs.

4.6 "İríriniàgblàlágbà fi ń ș'ogbọn"

Life experience is what translates into wisdom among elders

4.7 "Enitójìnsíkòtòkọ̀wonyòól'ọgọn"

He who falls into a pit teaches others a lesson (wisdom)

4.8"Ogbonologbonnikìijẹkí á peàgbàníwere"

Tapping the wisdom of others is what prevents an elder from being taggeda fool

These proverbs are statements of facts. They are the age-long wisdom-related proverbs among the Yorùbá. They illustrate the experience of the Yoruba regarding the development of wisdom in various circumstances. The first proverb states that the development of wisdom is facilitated by life experiences. In other words, wisdom doesn't develop in isolation. People only become wise by interacting with people and the environment and not without stimuli. The stimuli here are the life experiences which are time-related factors. As studies had shown, the older a person is, the more he or she is likely to become wise. This is why Yoruba considers the elders as the wisest in the community.

It must however be noted that the increase in wisdom with life experiences is not numerical but in quality and value and may not exhibit the mathematical relationship of direct proportion. Also, it should be noted that the life experiences can be from self or others. This was noted by Sternberg (1985) in his remark: 
"The wise individual is perceived to profit from the experience of others; and to learn from others' mistakes, as well as from his or her own"

The above statement underscores the role of interdependency at enhancing the development of wisdom. This is the basis of the second proverb. As deployed by the second proverb, whoever falls into a pit teaches others a lesson. Others in this context are those prepared to become wise and not those who wish to remain as fools. As a matter of fact, whoever learnt from the mistake of others is considered wise while someone who did not is a fool. This is the view of the tortoise (personified):

\section{İjàpání: “Omọtóbá fi orọararẹk’ogbonkìiśseomoòun, șùgbọn, èyìitóbá fi orọolorọk’ogbonniomoòun”}

The tortoise said:A child that makes mistakes before he learns is not his own child, but the one that learns from the mistake of others is his own child.

Thus, to learn from the mistakes of others is a condition that facilitates the development of wisdom. The third proverb goes thus; 'it is by tapping the wisdom of others that an elder wouldn't be tagged a fool. However, tapping the wisdom of others goes beyond mere copying and pasting. The philosophy of tapping entails watching, listening and analyzing before taking decisions. The wisdom to be tapped lies in the opinions of others. Thus, someone who is prepared to tap from the wisdom must allow others to speak and exhaust their opinions before he or she acts. It is from their opinions that he or she would extract the good and the bad, discards the bad and upholds the good. By the time he or she synthesizes and expresses his or her own opinions, he or she would stand tall and would not be tagged a fool but a wise person. This ability to lean on others for wisdom is reaffirmed by Sternberg (1985):

The wise individual listens to others, knows how to weigh advice, and can deal with a variety of different kinds of people in seeking as much information as possible for decision making; the wise individual reads between the lines as well as makes use of the obviously available information.

\section{9"Ogbonkiìtánláyékáwaloorun"}

Wisdom does not finish on earth that we may seek for it in heaven

Although not in physical term, wisdom is perceived by the Yorùbá as a commodity. With this perception, the Yorùbá believes, no one should be in want of wisdom when faced with the challenges of life. As previously established, wisdom is universal. Of course, universality does not imply availability in physical quantities; instead wisdom is believed to have many facets that can be used to resolve different crisis. As the popular saying goes, when one door is closed, another one is open. Once there is a will, there is always a way. In any challenge of life, there should be a way out. All that is required when it appears the road is closed is to look inward and apply wisdom to surmount the challenge. The proverb establishes the fact that the development of wisdom can be facilitated by different life experiences and that the cooperation between people could provide the necessary impetus to overcome a challenge.

4.10"Omo ò jìyà, ó ní, òúngbon.Tísàwolóko?"”

A child does not suffer, he claims to be wise. Who was his Teacher?

The Yorùbáhas noted that wisdom accrues to people over a period of time due to life experiences. Brown (2004a), using semi-structured interviews asked ten recent graduates to reflect on their undergraduate college experiences. He found that wisdom develops when students go through the core "learning-from-life" process and that the conditions that facilitate the development of wisdom by directly or indirectly stimulating the "learning-from-life" process are the student's (a) orientation to learning, (b) experiences, (c) interactions with others, and (d) environment. Thus, the Yorùbá's perception of the development of wisdom and conditions that facilitate the development tallies with the Brown's study. The proverb further authenticates the fact that wisdom does not develop in isolation. It requires interactions, communications and actions. The proverb is used for the counseling and to teach people that no one shakes the tree of life and bring down fruits. Success comes by dint of hard work prompted by the challenges of life.

The next two proverbs are meant to emphasize the roles of wisdom in the well-being of human being. The proverbs are deployed indirectly with antonyms of wisdom as the subject of the phrases.

4.11"Omo ò gbon, e nikósáàmátikú, kíló ń panibiàigbon" "

A child is born a fool, you said, he must not die, what else kills than being a fool

\subsection{2 "Eniàìgoọn pa lópo, ẹniogbọn pa kòtó nǹkan”}


Fools die in multitudes, only few die of wisdom

Wisdom is perceived by the Yorùbáas having ability to preserve, protect and prolong lives. A wise man is believed to live longer than the fool if all other factors are taken into consideration. Thus, 'to live long is to live wisely'. Although, studies on the association between wisdom and well-being have yielded conflicting results, there seem to be greater evidence of a positive association between wisdom and well-being. There are many ways by which wisdom may promote the well-being of human being. Firstly, wisdom by virtue of its nature, can sense and prevent dangers. For instance, a wise man would not take unnecessary risks.

Also, a wise man lives a discipline and exemplary life. Conversely, a foolish person may ignore warnings and safety guides thereby vulnerable to injuries and death. Probably this is what King Solomon had in mind when he wrote:

......... I have been calling you, inviting you to come, but you would not listen. You paid no attention to me. You have ignored all my advice and have not be willing to let me correct you. So when you get into trouble, I will laugh at you, I will mock you when terror strikes, when it comes on you like a storm, bringing fierce winds of trouble, and you are in pain and misery. (Proverbs chapter 1, verses 24-27).

Another point is that; the ability of a wise man to overcome the world with a sense of understanding and good judgement can nourish the soul and in-turn promotes the well-being of mankind. Basically, the above proverbs are meant to call attention to the importance of wisdom in well-being and longevity. The proverbs warn against pampering or promoting foolishness and mediocrity at the expense of wisdom. The wisdom and willingness to abide with the process of appointing Kings in Yorùbá land may account for the longevity commonly seen among their royal fathers as reflected in the next proverb.

4.13"Ologbonkanò fi ararẹobarí, omorànkan ò fi ararejj'oyè, wonmáa ń p'èèyànwájobani"

No wise man ever makes himself a king; no informed person ever makes himself achief. AKing is usually appointed by the people.

A cursory look at this proverb may fail to identify its deep-seated meanings. However, like most proverbs, it contains more content meanings than can be expected from its literary translation. Firstly, the proverb depicts the disposition of a wise man to power. Secondly, it states that a wise man would never make himself a king even though he is qualified to be a king. Thirdly, a wise man abides by the truth and does what is accepted as the norms. From this analysis, it is clear that wisdom does not impose but obeys the truth and complies with the norms. This may be a major factor in the longevity commonly associated with kingship in Yorùbásocio-cultural setting. Obviously, anyone who imposes himself as a king in Yorùbál and would face the consequences and may find it difficult to enjoy a peaceful reign. But for the wise man that follows due process, his reign will most likely be long and peaceful. Therefore, it would be tantamount to foolishness if any man imposes himself as a king when a WISE man chooses to obey the rule of the game. The proverb is used to warn people against imposition as this is not a feature of wisdom but of foolishness.

4.14 “Àáyágbọn, Ògúngbègbọn, Ȧáyá ń tiro, Ògúngbènáà ń bẹẹ”

The ape is wise and so is Ogungbe. As the ape limps, so Ogungbe squats

This story-derived proverb depicts a tactical move between an ape and a hunter in the bush. The ape is a tail-less monkey that can walk on two legs. On this day, the ape proved to be wise. On sighting a hunter, it begins to limp instead of walking upright. This movement produces alternate up and down posture so as to dodge the hunter. Realizing the gimmick, the hunter immediately squatted to avoid being sighted by the ape. Thus, as the ape limps up, the hunter squats and as the ape limps down, the hunter stands. With such tactical movement, wisdom was called to play by both the hunter and the hunted. Noting this, the Yorùbá adopts the proverb to illustrate the fact that wise individual does not succumb to subjugation and deceit. In other words, wisdom promotes equality and truth. The proverb also reaffirms the fact that nobody has monopoly of wisdom. It is used when someone wants to deceive fellow being under the guise of being wise.

4.15 "Enitóbáròpéòungbọn, tóròpéẹlòmuíràn ò gbọn, òungan-anni baba obo"

Whoever presumes to be wise and others are fools is the greatest fool on earth

This is the proverb that gives insight into the perception of Yorùbá about what wisdom is not. The proverb was generated from the observations that sometimes people in their own opinion presume to be wise and others are fools. The presumption may manifest in the form of deceit, cheating, imposition, exploitation, abuse of power, oppression, pride and refusal to learn from others. It could also mean that the culprit wants to play the role of ' $\mathrm{Mr}$ 
knows all' or play upon the intelligence of others. In all these circumstances, the Yorùbá has noted that the assumptions amount to nothing but emptiness. Firstly, such an individual is ignorant of the fact that wisdom is universal and that nobody has monopoly of wisdom. Secondly, what he or she considers as wisdom is no more than intelligence, cleverness or craftiness. Thirdly, such an individual is ignorant of the fact that being egocentric can be counterproductive. Therefore, for anyone with these negative attributes to claim monopoly of wisdom in deeds and behaviours is nothing but foolishness of the highest order.

This is the contention of the Yorùbáas expressed in the above proverb. The proverb is used to warn people against exploitation and abuse of power under the guise of being wise. The proverb makes us to understand that wisdom is not egotism or other negative virtues. Rather, wisdom is a universal virtue that helps human being to understand, deal with and succeed in the world without hurting the soul of mankind.

\section{Conclusion}

This work has attempted to describe the Yorùbá's perception of wisdom in the context of proverbial expression. The study reveals that Yorùbá had over time developed proverbs that reflect her own understanding of the nature and functionalities of wisdom. It reaffirms the fact that proverbs can be used to reveal the common-cultural views that dominate the thinking about a specific psychological construct. So far, the study has answered four important questions about wisdom: What is wisdom? What conditions facilitate its development? What roles does it play in human life? What are the things that are not wisdom? The fifteen selected (Yorùbá) proverbs define wisdom as sense of understanding and good judgement with ability to know the consequences of actions. The conditions that facilitate its development are life experiences and interpersonal relationship. Wisdom plays significant roles in conflict resolution, offering solutions to life problems and promoting human well-being. However, the Yorùbárecognizes imposition and tendency to cheat under the guise of being wise as nothing but stupidity.

It is important to note that this study only focus on the Yorùbá's perception of wisdom using proverbs as indirect markers. Thus, according to Sternberg (2001), the goal is not to provide a "psychologically true" account of wisdom, but rather an account that is true with respect to people's beliefs. Nevertheless, the study had established the fact that the Yorùbá has over the years studied and recognized the distinct nature of wisdom. With this background information, the stage is now set in our own setting for future studies particularly in the area of biological markers of wisdom. For instance, does wisdom runs in family? Is there a genetic basis for wisdom? If yes, is there a distinct genetic locus? Does wisdom has a specific locus in the brain? Is there a biological inducer of wisdom? At what age does wisdom begins to manifest? Does hormone play roles in the growth and development of wisdom? Can wisdom be medically influenced? Until we are able to answer these and other pertinent questions in the minds of researchers using human or animal studies, the story about wisdom has not ended.

\section{References}

Adamo, D.T. (2015). Ancient Israelite and African proverbs as advice, reproach, warning, encouragement and explanation', HTS Teologiese Studies/Theological Studies 71(3), Art.\#2972, 11pages. http://dx.doi.org/10.4102/hts.v71 i3.2972

Ademowo A. J, Balogun N.O (2014). Proverbs, Values and the Development Question inContemporary Africa: A Case Study of Yoruba Proverbs. Antropologija 14 (2)149-161.

Adeyemi B.A, Salawudeen M.O. (2014) The Place of Indigenous Proverbs in PeaceEducation inNigeria: Implications for Social Studies Curriculum. InternationalJournal of Humanities and Social Science 4(2) special issue; 186-192.

Ardelt M (2000). Intellectual versus Wisdom-Related Knowledge: The Case for a DifferentKind of Learning in the Later Years of Life. Educational Gerontology, 26:771-789

Ardelt M (2000). Antecedents and Effects of Wisdom in Old Age.A Longitudinal Perspectiveon Aging Well.Research on Aging, 22(4):360-394.

Bailey H, Love M (2008).Sayings of the great.In Bailey and Love's SHORTPRACTICE of SURGERY. $25^{\text {th }}$ Ed, Norman S. Williams, Christopher J.K Bulstrode, P.Ronan O'Connell (Eds). Hodder Arnold. London, UK. Page xvii.

Baltes P.B, Staudinger U.M (1993). The Search for a Psychology of Wisdom.CurrentDirections in Psychological Science.2(3) $75-80$. 
Brown, S. C. (2004a). Learning across campus: How college facilitates the development of wisdom.Journal of College Student Development, 45, 134-148.

Brown S.C, Greene J.A (2006 ). The Wisdom Development Scale: Translating the Conceptual to the Concrete. Journal of College Student Development.47(1) 1-19.

Clayton V (1982). Wisdom and intelligence: the nature and function of knowledge in thelater years. Int J Aging Hum Dev. 15(4):315-21.

Fasiku G. (2006). Yoruba Proverbs, names and national consciousness. Journal of PanAfricanStudies. 1(4): 5063.

King Solomon (2010).. Wisdom Calls. In The Book of Proverbs, The Good News Bible withDeuterocanonical Books, India, Swapna Printing Works Pvt. Ltd. Chapter 1: Verse20-28.574-575.

Olatunji M .O (2012).Yoruba Proverbs and Musicality.Legon Journal of the Humanity.23:125-140.

Staudinger, U. M., \&Glück, J. (2011). Psychological wisdom research: Commonalities anddifferences in a growing field. Annual Review of Psychology, 62:215-41. doi:10.1146/annurev.psych.121208.131659.

Sternberg, R. J. (1985). Implicit theories of intelligence, creativity, and wisdom.Journalof Personality and Social Psychology, 49,(3): 607-62.

Sternberg R.J (2001). Why Schools Should Teach for Wisdom: The Balance Theory of Wisdom in Educational Settings. Educational Psychologist, 36(4), 227-245.

Trench, R.C. (1905) Proverbs and their lessons, with additional notes and bibliography ofproverbsby A Smythe Palmer. London. George Routledge\& Sons, Limited.New York: E.P. Dutton \& Co

Wikipedia.Wisdom.Accessed @ https://en.wikipedia.org/wiki/wisdom.on 08-10-2018.

William Cowper (1978). Knowledge and Wisdom.Pediatrics.61:555.

Zacher H, Staudinger U. M. (2018). Wisdom and well-being.In E. Diener, S. Oishi, \& L. Tay (Eds.), Handbook of well-being. Salt Lake City, UT: DEF Publishers. DOI:nobascholar.com. 